\title{
Neck pain in South Africa: An overview of the prevalence, assessment and management for the contemporary clinician
}

\begin{tabular}{|c|c|}
\hline \multicolumn{2}{|c|}{$\begin{array}{l}\text { Authors: } \\
\text { Cato A. Basson }{ }^{1} \\
\text { Benita Olivier } \\
\text { Alison Rushton }^{2}\end{array}$} \\
\hline \multicolumn{2}{|c|}{$\begin{array}{l}\text { Affiliations: } \\
\text { 1Department of } \\
\text { Physiotherapy, University } \\
\text { of the Witwatersrand, } \\
\text { Johannesburg, South Africa }\end{array}$} \\
\hline \multicolumn{2}{|c|}{$\begin{array}{l}{ }^{2} \text { Centre of Precision } \\
\text { Rehabilitation for Spinal Pain } \\
\text { (CPR Spine), School of Sport, } \\
\text { Exercise and Rehabilitation } \\
\text { Sciences, University of } \\
\text { Birmingham, Edgbaston, } \\
\text { United Kingdom }\end{array}$} \\
\hline \multicolumn{2}{|c|}{$\begin{array}{l}\text { Corresponding author: } \\
\text { Cato Basson, } \\
\text { bassonannalie@gmail.com }\end{array}$} \\
\hline \multicolumn{2}{|c|}{$\begin{array}{l}\text { Dates: } \\
\text { Received: } 22 \text { Jan. } 2019 \\
\text { Accepted: } 25 \text { June } 2019 \\
\text { Published: } 04 \text { Sept. } 2019\end{array}$} \\
\hline \multicolumn{2}{|c|}{$\begin{array}{l}\text { How to cite this article: } \\
\text { Basson, C.A., Olivier, B. \& } \\
\text { Rushton, A., 2019, 'Neck pain } \\
\text { in South Africa: An overview } \\
\text { of the prevalence, assessment } \\
\text { and management for the } \\
\text { contemporary clinician', } \\
\text { South African Journal of } \\
\text { Physiotherapy 75(1), a1332. } \\
\text { https://doi.org/10.4102/sajp. } \\
\text { v75i1.1332 }\end{array}$} \\
\hline \multicolumn{2}{|c|}{$\begin{array}{l}\text { Copyright: } \\
\text { (C) 2019. The Authors. } \\
\text { Licensee: AOSIS. This work } \\
\text { is licensed under the } \\
\text { Creative Commons } \\
\text { Attribution License. }\end{array}$} \\
\hline \multicolumn{2}{|l|}{ Read online: } \\
\hline 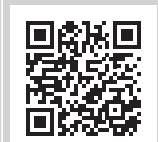 & $\begin{array}{l}\text { Scan this QR } \\
\text { code with your } \\
\text { smart phone or } \\
\text { mobile device } \\
\text { to read online. }\end{array}$ \\
\hline
\end{tabular}

Background: Neck pain is a prevalent condition and is associated with high levels of disability and pain. The long-term prognosis can be poor, and therefore effective management in the acute stage is important.

Objectives: To provide an overview of the prevalence of neck pain and physiotherapy management and to provide evidence-informed recommendations for clinical practice within a South African context.

Method: The literature was reviewed considering prevalence, risk factors and examination. Management recommendations were derived from the highest levels of evidence of clinical practice guidelines, systematic reviews and randomised clinical trials.

Results: Neck pain is classified into four grades, and three trajectories of recovery have been identified. Although the incidence of neck pain globally is high, in the South African context the majority of the population have limited access to physiotherapy management. Sound clinical reasoning is important in the assessment and decision-making process for management. Exercise, and mobilisation or manipulation are effective treatment options in the management of most types of neck pain. Other physical modalities such as needling, transcutaneous electrical nerve stimulation, laser and intermittent traction may be used as an adjunct to management.

Conclusion: The burden of neck pain globally is high; however, there is a lack of information on current practice, prevalence and burden of neck pain in the South African context. Sound evidence-informed clinical reasoning to inform a working diagnosis and to enable patientcentred management is important.

Clinical implications: A thorough assessment is essential to gather information to formulate hypotheses regarding diagnosis and prognosis for neck pain. Exercise, and mobilisation or manipulation are effective management options.

Keywords: neck pain; prevalence; assessment; management; risk factors; South Africa; physiotherapy.

\section{Introduction}

Neck pain is one of the most common debilitating musculoskeletal complaints affecting the population (Hoy et al. 2014). In the 2015 Global Burden of Disease report, low back pain and neck pain were the leading causes of disability (Vos et al. 2016). Hoy et al. (2014:1309) defined neck pain as 'pain in the neck with or without referred pain into one or both upper limbs' and performed a systematic review to evaluate incidence, prevalence, duration and mortality risk of neck pain.

The considerable burden of disease from neck pain necessitates the effective translation of research findings into clinical practice. This article aims to give an overview of the prevalence of neck pain and physiotherapy management of neck pain and to make evidence-informed recommendations for application into clinical practice within a South African context.

\section{Prevalence and incidence of neck pain}

From systematic review data, the prevalence of neck pain over a 12-month period was documented as $30 \%-50 \%$ (Hogg-Johnson et al. 2008), with a point prevalence of $4.7 \%$ and a lifetime prevalence of $14.2 \%-70 \%$ dependent on the country where it was measured (Hoy et al. 2014). The point prevalence of neck pain in the sub-Saharan Southern Africa region is high 
(males 4.7\%; females 6.7\%) and is only outranked by the United States (males 5.3\%; females 7.6\%), Western Europe (males 5.2\%; females 7.4\%) and East Asia (males 4.8\%; females 7.0\%) (Hoy et al. 2014; Vos et al. 2012). There was also a significant increase of neck pain prevalence between 1990 and 2015 (Hurwitz et al. 2018). Possible reasons cited for the increase in neck pain are an ageing population and increasing obesity (Hurwitz et al. 2018). From estimates for the global burden of neck pain (2000-2010), it was found that neck pain is more prevalent in women compared to men and peaks between 40 and 50 years of age (Hoy et al. 2014).

Few studies exist on the incidence of neck pain in the South African population (Brink et al. 2009; Mafanya \& Rhoda 2011; Smith et al. 2009). Most of these only included an adolescent population. In a study of risk factors for developing neck pain amongst 181 adolescents in South Africa (SA), the incidence of neck pain was $53.7 \%$ (Mafanya \& Rhoda 2011). Smith et al. (2009) reported a $20 \%$ incidence of neck pain in adolescent computer users $(n=1073)$, and similarly an incidence of $26 \%$ of neck pain was documented in a study on the sitting posture of South African adolescents (Brink et al. 2009). The incidence of musculoskeletal disorders of office workers in a private hospital in SA (Zungu \& Ndaba 2009) was found to be $76 \%$ musculoskeletal complaints, with low back pain being the most common complaint followed by neck pain. In private physiotherapy practices in Pretoria, 46\% of the musculoskeletal complaints seen by physiotherapists were patients with neck pain (Basson et al. 2017b).

\section{Burden of neck pain and access to health care in South Africa}

Estimates of the burden of disease for SA in 2000 ranked musculoskeletal disorders 20th (Bradshaw et al. 2003), and the World Health Organization (2010) ranks it 16th from a more recent fact sheet on health statistics (1990-2008). In a primary care setting in SA, neck pain is ranked 34th as a main complaint for consultation (Mash et al. 2012). According to Rice, Smith and Blyth (2016), there is little information available for sub-Saharan Southern Africa in terms of the global burden of pain. The lack of data may be part of the reason for the large discrepancy in the ranking of musculoskeletal diseases in SA compared to the global burden of disease (Hoy et al. 2014; Vos et al. 2012)

The majority $(84 \%)$ of the South African population use public health care. These facilities are often understaffed with limited resources (Ranchod et al. 2017). Prolonged waiting times in the public sector, mainly because of resource limitations, play a major role in the effective management of patients with neck pain (Hasumi \& Jacobsen 2014). Access to public health care facilities depends on the area, with access often limited in rural areas because of distance from a facility and transport difficulties (National Department of Health 2015). Therefore, access to physiotherapy is also limited.
There are 7698 physiotherapists registered in SA (Health Professions Council of South Africa 2018) of whom only 1258 are employed in public health care (National Department of Health 2015). Furthermore, of the 4595 physiotherapists who are members of the South African Society of Physiotherapists (SASP), 3671 work in the private sector (SASP data November 2017). Access to the private sector requires self-payment or membership of a medical insurance scheme. It could therefore be hypothesised that the majority of South African society will not have easy access to public health care facilities and physiotherapy management for neck pain. This may change when the National Health Insurance (NHI) is adopted (National Department of Health 2016) as it aims to make essential health care available to all South African citizens.

\section{Classification of neck pain}

The Bone and Joint decade task force on neck pain and the Global Spine Care Initiative classify neck pain into four grades using a best evidence synthesis (Guzman et al. 2009; Haldeman et al. 2018) (S21 \& S889).

Grade I - neck pain with no signs of major pathology and no or little interference with daily activities; Grade II - neck pain with no signs of major pathology, but interference with daily activities; Grade III - neck pain with neurologic signs of nerve compression; Grade IV - neck pain with signs of major pathology.

This classification system is also used in the recently updated Dutch clinical guidelines for neck pain (Bier et al. 2018). In contrast, the American Physical Therapist Association (APTA) clinical guidelines use a different classification system, namely neck pain with mobility difficulties; neck pain with movement control difficulties; neck pain with radiating pain; and neck pain with headache (Blanpied et al. 2017). For the purpose of this article, we will use the Global Spine Care Initiative definition (Haldeman et al. 2018) rather than the APTA classification (Blanpied et al. 2017), as it can be difficult to differentiate between mobility problems and control problems and they often overlap. We will also briefly discuss neck pain associated with headache and neck pain because of whiplash injury.

\section{Clinical course and risk factors for neck pain and recovery from neck pain}

Three trajectories of recovery from neck pain have been identified (Van Hulst et al. 2016; Walton et al. 2014a). Rapid recovery over a month period is present in $19.6 \%$ of the neck pain population, $65.8 \%$ of patients have a modest rate of recovery (i.e. a non-significant decrease in pain and disability over a month period) and $14.6 \%$ have a pattern of worsening symptoms (Walton et al. 2014a). First onset neck pain tends to improve in the first 6 weeks after which symptoms often remain unchanged at 12-month follow-up (Hush et al. 2011; Vasseljen et al. 2013). Therefore, only around $20 \%$ of the neck 
pain population will recover well, and overall, the prognosis of acute neck pain is poor according to a systematic review and meta-analysis (Hush et al. 2011). At 12-month follow-up, the majority of patients still present with high pain severity and disability (Hush et al. 2011). A number of factors have high to moderate predictive power for the development of chronic pain (Walton et al. 2013).

Risk factors for first onset neck pain were found to be working in awkward positions (OR 1.65; 95\%CI 1.04-2.60), sustained positions (OR 1.80; 95\%CI 1.16-2.81) and psychosocial factors such as high job demands (RR 2.14; 95\%CI 1.28-3.58) and co-worker support (RR 2.43; 95\%CI 1.11-5.29) (Kim et al. 2018). Risk factors for poor prognosis from neck pain at baseline are high levels of pain (OR 5.61, 95\%CI 3.74-8.43) and disability (NDI > 15/50; OR 42.18) at baseline (Walton et al. 2013). Other studies have highlighted the importance of psychosocial factors such as catastrophising (Karels et al. 2007; Thompson et al. 2010) and fear-avoidance beliefs (Karels et al. 2007; Pool et al. 2010) as risk factors for chronicity.

Social factors such as work-family imbalance and a hostile work environment have also been linked to a high prevalence of neck pain (Yang et al. 2016). In working populations, high job strain (OR 1.5 [95\% CI 1.0 to 2.4]) and sleep disturbances (OR 2.2 [95\% CI 1.6 to 3.0]) are associated with chronic neck pain (Rasmussen-Barr et al. 2014). Nonmodifiable risk factors identified are being female and of older age (Walton et al. 2013). Longer duration of symptoms, absence of paraesthesia, a high neck pain intensity, disability at baseline and restricted range of movement (ROM) towards the affected side are found to be factors related to poor recovery of pain and disability (median under the curve 0.75-0.79) in cervical radiculopathy, a subgroup of neck pain (Sleijser-Koehorst et al. 2018).

Neck pain is often associated with headache, upper back and shoulder or arm pain (Lindgren 2008; Salt et al. 2011). In a study of over 1800 patients, only $36 \%$ presented with neck pain alone and the remainder of the population had neck pain and radiating arm pain (Rasmussen et al. 2015). Radiating neck and arm pain and headache can have a negative impact on disability and quality of life (Daffner et al. 2003; De Pauw et al. 2015). Neuropathic pain is often present in patients with cervical radiculopathy (Tampin, Slater \& Briffa 2013) and whiplash-associated disorders (WAD) (Sterling \& Pedler 2009). On the website of the International Association for the Study of Pain, neuropathic pain is described as 'pain initiated or caused by a primary lesion or dysfunction in the nervous system' (International Association for the Study of Pain 2011). The presence of neuropathic pain has a negative impact on quality of life (Doth et al. 2010; Smart et al. 2012; Smith et al. 2007) and is also associated with disability and poor treatment outcomes (Blyth 2017; Doth et al. 2010). Table 1 summarises the risk factors for poor recovery reported by Jakobsen et al. (2018), Kim et al. (2018) and Walton et al. (2013).
TABLE 1: Predictors of poor recovery.

\begin{tabular}{ll}
\hline Risk factor & Confidence \\
\hline High baseline pain & High \\
High baseline disability & High \\
Older age & Moderate \\
Psychosocial factors & Moderate \\
Working in awkward positions & Low \\
History of other musculoskeletal disorders (MSK) disorders & Low \\
\hline
\end{tabular}

\section{Assessment of patients with neck pain}

Sound clinical reasoning is important to guide decisionmaking (Bier et al. 2018; Edwards et al. 2004; Rushton et al. 2014), and critical use of evidence should underpin the clinical reasoning process. According to Sackett et al. (1996), evidence-informed practice takes into account the best current research evidence, clinical expertise and patient preferences. Before deciding on management options, it is necessary to exclude serious pathology (Guzman et al. 2009) and refer patients with red flags for further investigation or to another health care practitioner. It is also important to determine whether the pain is acute ( $<6$ weeks since onset), sub-acute (6-12 weeks since onset) or chronic in nature (> 3 months duration). The treatment approach may differ between a patient with acute neck pain and one with chronic neck pain. The management of chronic pain is often more complex and can be treatment resistant (Cohen \& Hooten 2017). Planning of the patient assessment is shown in Figure 1, while the various components that form part of the patient examination are shown in Figure 2.

\section{Patient history}

The patient history is essential to gather information in order to formulate hypotheses regarding diagnosis and prognosis as well as the psychosocial context of the patient, and to identify the presence of possible red flags. The International Federation of Orthopaedic Manipulative Physical Therapists (IFOMPT) developed an international framework for the examination of the cervical spine for cervical arterial dysfunction (CAD) (Rushton et al. 2014). In the clinical reasoning process, examination for risk factors for CAD prior to using any manual therapy techniques on the cervical spine can assist to prevent adverse events (Hutting et al. 2018; Rushton et al. 2014). The physiotherapist should aim to identify factors that may potentially implicate neurovascular pathology or are indicative of contraindications to treatment (Rushton et al. 2014).

\section{Patient reported outcome measures}

Patient reported outcome measures (PROMs) assist the clinician in establishing baseline characteristics such as pain, function, disability, quality of life and psychosocial factors. These measures also help to monitor the patient throughout the course of treatment enabling evaluation of treatment interventions and progression of interventions (Kuhn 2016). Additionally, it is proposed that the area of pain (body chart), 


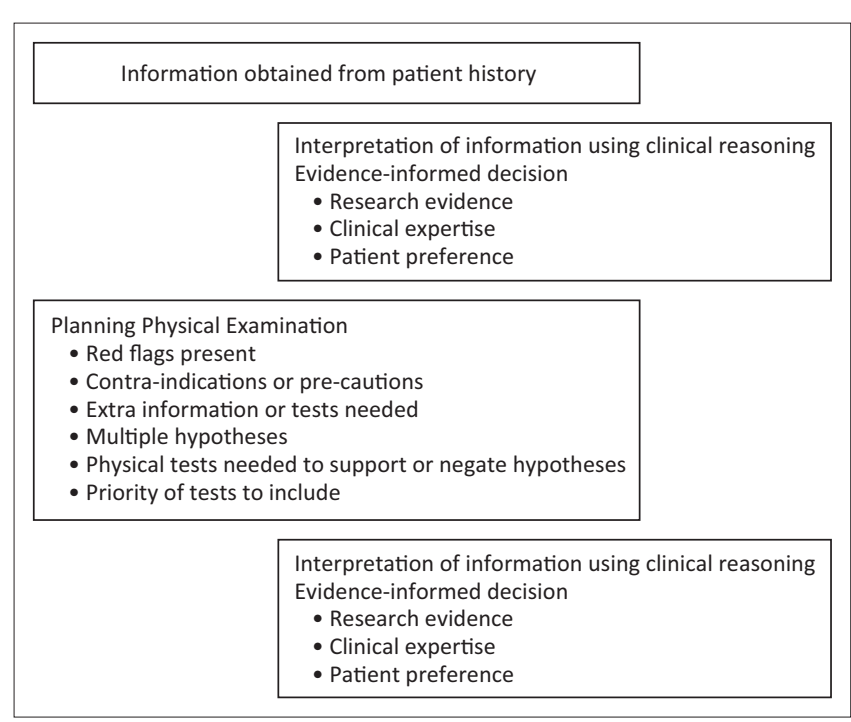

FIGURE 1: Planning the physical examination.

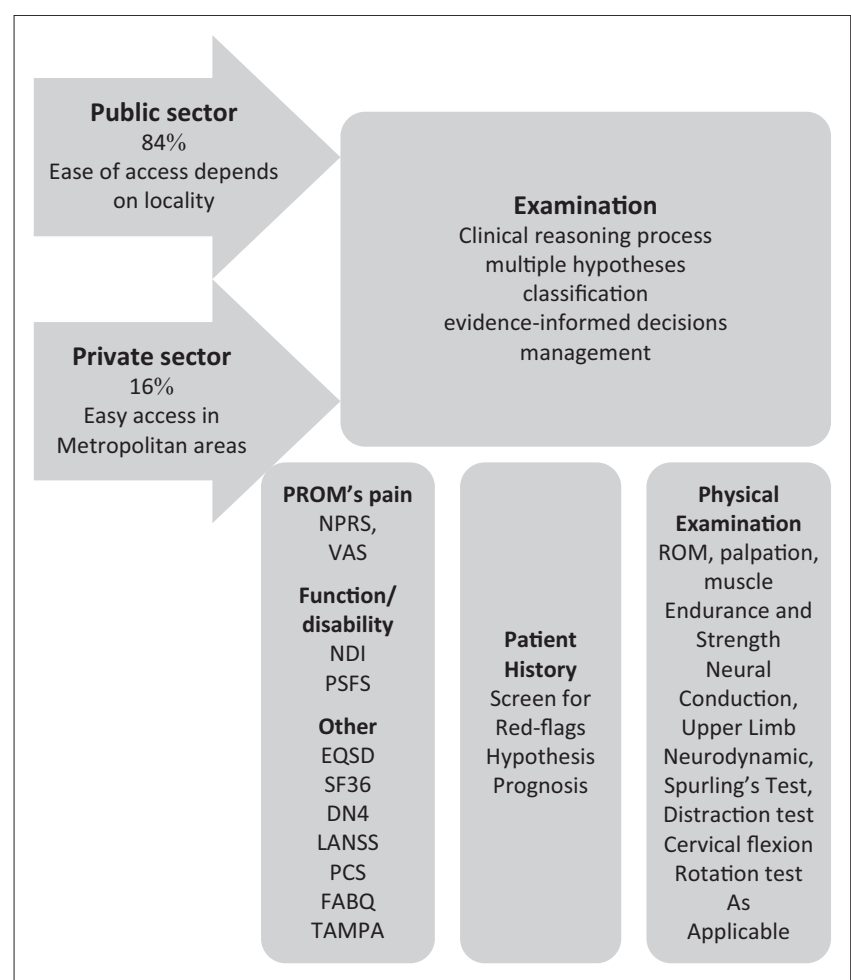

PROMs, Patient Reported Outcomes; NPRS, Numerical Pain Rating Scale; VAS, Visual Analogue Scale; NDI, Neck Disability Scale; PSFS, Patient Specific Functional Scale; EQ5D, Euroqual 5D Instrument; SF36, Short Form Health Survey; DN4, Neuropathic Pain Questionnaire; LANSS, Leeds Assessment of Neuropathic Signs and Symptoms; PCS, Pain Catastrophising Scale; FABO Fear Avoidance Beliefs Questionnaire; Tampa, Tampa Scale of Kinesiophobia.

FIGURE 2: Patient examination.

behaviour of pain, pain intensity and quality of pain are documented (Fillingim et al. 2016). The multiple domains of pain (e.g. sensory, cognitive and affective) should also be assessed. This information can assist in the classification of the type of pain and possible underlying pathophysiological mechanisms (Fillingim et al. 2016).

The Numeric Pain Rating Scale and the Visual Analogue Scale are commonly used to measure pain. Both are reliable and sensitive to change (Holdgate et al. 2003). The Neck Disability Index and Patient Specific Functional Scale are recommended by current guidelines to measure function and disability (Bier et al. 2018; Blanpied et al. 2017). Other useful PROMs are the SF36 and EuroQual 5D Instrument to measure health-related quality of life (Coons et al. 2000). There is an array of instruments to assess psychosocial factors (Turk et al. 2016). The Fear-Avoidance Beliefs Questionnaire (Waddell et al. 1993) and the Tampa Scale for Kinesiophobia are valuable instruments used to assess the presence of fear-avoidance beliefs or kinesiophobia in the patient (Miller, Kori \& Todd 1991). The Pain Catastrophising Scale can be used to assess the presence of high pain catastrophising (Sullivan, Bishop \& Pivik 1995). The Diagnostic Pain Questionnaire (DN4) (Bouhassira et al. 2005) is recommended for use by the 'South African Management of Neuropathic Pain Guidelines' (Chetty et al. 2012:315) to assess the presence of neuropathic pain. The Leeds Assessment of Neuropathic pain, Signs and Symptoms (S-LANNS) is also advocated (Haanpää et al. 2011) to assess for the presence of neuropathic pain (Bennett 2001).

\section{Physical examination}

Planning of the physical examination plays an important role in the effectiveness of the execution of the physical examination and is outlined in Figure 2. The physical examination enables testing of working hypotheses regarding diagnosis and prognosis. Active movement tests can be a valuable tool to establish a baseline and to monitor change over time (Blanpied et al. 2017). However, clinicians should not rely solely on ROM to make clinical decisions as other factors may play an important role in clinical presentation and prognosis (Snodgrass et al. 2014). Tools that are commonly used to measure the cervical ROM are the cervical range of motion (CROM) device (Performance Attainment Associates, Lindstrom, MN), the inclinometer and the standard goniometer (ICCs range between 0.89 and 0.98) (Audette et al. 2010; Snodgrass et al. 2014). Because of financial constraints in a SA context, use of the goniometer would be a common choice.

Passive accessory intervertebral movements of the cervical and thoracic spine can be useful, but reliability is poor to moderate except for assessing $\mathrm{C} 1 / \mathrm{C} 2$ and $\mathrm{C} 2 / \mathrm{C} 3$ levels (Hall et al. 2008). Reliability of the upper cervical mobility tests is better in symptomatic compared to asymptomatic participants (reliability fair: symptomatic range $\kappa 0.21-0.40$ ) (Van Trijffel et al. 2005).

Neck pain may be because of specific causes such as fracture, inflammatory disease and neurological compromise. However, for most of the neck pain population, an insidious onset is the cause of neck pain and therefore referred to as non-specific neck pain (Hoving et al. 2006).

Rubinstein et al. (2007) found that a cluster of tests aided in diagnosing cervical radiculopathy. These tests include neck rotation $<60^{\circ}$, a positive Spurling test, a positive Valsalva test and a positive neck distraction test. If three of the tests are positive, the probability of being a positive cervical 
radiculopathy was determined as 65\% (6.1 [2.0-18.6]) (Wainner et al. 2003). A negative Upper Limb Neurodynamic Test (median nerve bias) would rule out cervical radiculopathy (Rubinstein et al. 2007).

The cervical flexion rotation test is a valid and reliable test to diagnose and evaluate cervicogenic headache (Hall et al. 2008; Rubio-Ochoa et al. 2016). Manual examination by means of palpation is a sensitive test to discriminate between cervicogenic headache and other headaches (Zito, Jull \& Story 2006).

There is evidence that patients with radiating arm pain have sensory abnormalities (Moloney, Hall \& Doody 2015). Therefore, it is advisable to perform neural conduction testing and, if the physiotherapist has access to an algometer, to test pressure pain threshold (Walton et al. 2014b).

\section{Management}

The above process of examination enables a working hypothesis for diagnosis to enable the development of an individual patient management plan. Most guidelines recommend a combination of treatment modalities in the management of neck pain (Bier et al. 2018; Blanpied et al. 2017; Bussières et al. 2016; Childs et al. 2008; Cohen \& Hooten 2017). The management options discussed below are derived from clinical practice guidelines (Bier et al. 2018; Blanpied et al. 2017), systematic reviews and randomised clinical trials. Table 2 outlines the levels of evidence used (Phillips et al. 2009).

It is also important to differentiate between acute and chronic pain as this will determine the treatment approach (Grichnik \& Ferrante 1991). Acute and sub-acute pain is described as the pain caused by an injury or disease and of recent onset. Chronic pain is pain that has been present for longer than 3 months and persists past normal tissue healing (Merskey \& Bogduk 2011). In acute pain, treatment is aimed at the underlying cause, while treatment of chronic pain should be multimodal in nature (Grichnik \& Ferrante 1991).

\section{Acute and sub-acute grades I and II neck pain}

This describes neck pain with no signs of major pathology and either without (Grade I) or with (Grade II) interference

\begin{tabular}{|c|c|}
\hline Level & Type of evidence \\
\hline $1 \mathrm{~A}$ & Systematic review (with homogeneity) of randomised controlled trials (RCTs) \\
\hline $1 B$ & Individual RCT (with narrow confidence intervals) \\
\hline $1 C$ & All or none study \\
\hline $2 \mathrm{~A}$ & Systematic review (with homogeneity) of cohort studies \\
\hline 2B & Individual cohort study (including low-quality RCT, e.g. $<80 \%$ follow-up) \\
\hline $2 \mathrm{C}$ & ‘Outcomes’ research; ecological studies \\
\hline $3 \mathrm{~A}$ & Systematic review (with homogeneity) of case-control studies \\
\hline 3B & Individual case-control study \\
\hline 4 & Case series (and poor quality cohort and case-control study) \\
\hline 5 & Expert opinion \\
\hline
\end{tabular}

with daily activities. These grades include non-specific neck and arm pain without any neurological compromise (Haldeman et al. 2018).

\section{Mobilisation or manipulation}

Level IA evidence supports mobilisation or manipulation for acute and sub-acute neck pain to improve pain and function in the short and medium term (Gross et al. 2015). This is in line with guideline recommendations (Bier et al. 2018; Blanpied et al. 2017). Thoracic manipulation can also be useful in the management of non-specific neck pain (Huisman, Speksnijder \& De Wijer 2013) (Level IB). The decision regarding the choice between mobilisation and manipulation should be made after careful examination, clinical reasoning and assessment of risks and benefits.

\section{Exercise}

The evidence for exercises in acute neck pain is not robust, but the APTA guidelines recommend isometric strengthening and mobilising exercises (Blanpied et al. 2017). Mobilising exercises are effective for acute WAD (Teasell et al. 2010a). Strengthening exercises should be loaded progressively as aggressive strengthening exercises may aggravate pain during the healing phase (Teasell et al. 2010b) (Level 1A).

\section{Advice to stay active}

In patients with acute WAD (Teasell et al. 2010c) (Level 1A) and with acute neck pain (Bier et al. 2018) (Level 5), advice to remain active and continue with daily activities is recommended.

\section{Other interventions}

Other interventions that can be useful as an adjunct to mobilisation or manipulation and exercise are transcutaneous electrical nerve stimulation (TENS) (Kroeling et al. 2013) and dry needling (Mejuto-Vázquez et al. 2014) (Level 1B). The evidence does not support the use of a collar for acute neck pain as a collar may delay recovery in patients with acute WAD (Teasell et al. 2010c) (Level 1A).

Wirth, Humphreys and Peterson (2016) showed significant improvements in psychological parameters within the first month of acute and sub-acute neck pain. Therefore, if patients have not recovered as expected during the first month, psychosocial parameters should be re-evaluated and alternative management options explored.

\section{Chronic Grade I and II neck pain \\ Mobilisation or manipulation and exercise}

Cervical and thoracic mobilisation are advocated to improve pain and function in the short and intermediate terms (Gross et al. 2015) (Level 1A). A recent systematic review found that cervical, shoulder and scapula-thoracic strengthening exercises are effective in reducing pain and function over the short, intermediate and long term in chronic neck pain (Gross et al. 2016) (Level 1A). Some studies suggest that the combination of 
exercise and mobilisation or manipulation has a better effect than either alone (Miller et al. 2010). However, a more recent review found that the combination of exercise and mobilisation or manipulation is not more effective than either alone (Fredin \& Lorås 2017) (Level 1A). As the effect of exercise is evident over the long term (Gross et al. 2016) and mobilisation or manipulation has short-term, medium and long-term effects on pain and disability in chronic neck pain (Gross et al. 2015), a combination of the two seems like a feasible option. Another recent review found that general exercise does not improve long-term pain and disability in patients with WAD (Griffin, Leaver \& Moloney 2017).

\section{Other interventions}

There is good evidence for the use of neuroscience education for chronic musculoskeletal pain (Louw et al. 2011) and emerging evidence for its use specifically for chronic neck pain (Malfliet et al. 2018) (Level 1B).

As is the case in acute or sub-acute neck pain, dry needling and TENS can be used as an adjunct in chronic neck pain (Level 1A). Acupuncture, intermittent traction and laser are better than placebo for chronic neck pain (Graham et al. 2013) (Level 1A). A guideline developed for chiropractors recommends multimodal treatment and advice for patients with chronic WAD (Bussières et al. 2016).

\section{Neck pain with radiating arm pain (Grade III)}

Grade III neck pain refers to neck pain with neurological signs of nerve compression or irritation such as cervical radiculopathy (Haldeman et al. 2018). There is limited evidence for the optimal management of radiating arm pain (Salt et al. 2011; Thoomes et al. 2013). However, according to systematic reviews and guideline recommendations, some evidence exists for exercise, manual therapy, intermittent traction and low level laser (Blanpied et al. 2017; Graham et al. 2013; Salt et al. 2011). Neural mobilisation improves pain in radiating neck and arm pain but the impact of neural mobilisation on function and disability is conflicting (Basson et al. 2017a) (Level 1A). Neck-specific exercises may improve pain and function in patients with WAD and signs of neurological deficit (Landén Ludvigsson, Peterson \& Peolsson 2018) (Level 2B).

\section{Neck pain with headache}

For acute, sub-acute and chronic headache, the use of cervical mobilisation or manipulation with strengthening exercises is most effective in decreasing pain in patients with cervicogenic headache (Racicki et al. 2013) (Level 1A). This is also in line with the guideline recommendation (Blanpied et al. 2017). The C1/2 self-snag can be used as a home exercise to relieve pain in headache (Racicki et al. 2013) (Level 1B).

\section{Neuropathic pain}

Neuropathic pain is common in chronic pain populations and nerve-related pain populations (Blyth 2017). There is limited evidence for the use of physiotherapy to manage neck pain associated with neuropathic pain (Day et al. 2014). A multimodal treatment approach incorporating postural education, scapular stabilisation, neural mobilisation exercises, manual therapy and stretching exercises improves pain, disability and grip strength in patients with peripheral neuropathic pain (Level 2B). There is experimental evidence that exercise can improve pain (Cooper, Kluding \& Wright 2016); however, more research is needed on the conservative management of neuropathic pain.

\section{Implications for private sector and public sector}

Physiotherapists in the private sector will be in a position to use different modalities taking into consideration patient preference and available evidence. However, in the public sector, where physiotherapists will often only see a patient once, the aim should be to provide exercises and information on self-management. For both the private and public sector, the ultimate aim should be for the patient to manage a chronic condition independently and to reduce the risk of recurrences in the case of an acute or sub-acute condition. Aligning the patient management approach to the South African context is crucial.

South Africa has a unique multicultural landscape which calls for addressing the associated challenges surrounding communicative competence with regard to improving interviewing and counselling skills, intercultural and gender competencies, and linguistic and interpretation skills (Grant 2006). The management strategies to be considered for patients with neck pain are shown in Figure 3.

\section{Future directions}

There is a dearth of information on neck pain prevalence and physiotherapy management in a South African context. There is a need for the development of culturally appropriate PROMs in different languages to assist in the assessment of patients. Risk factors for the development of neck pain and disability may differ in a multicultural environment (Geere et al. 2018) and should be further explored. Furthermore, the ideal management of neck pain in terms of patient outcomes and economic viability in a culturally diverse environment deserves urgent attention.

\section{Conclusion}

Physiotherapists should use sound clinical reasoning to inform decisions pertaining to a working hypothesis and patient management in a patient-centred manner taking into account available evidence. The burden of neck pain globally is high; however, there is a lack of information on current practice, prevalence and burden in the South African context. The need for research on the prevalence and management of neck pain in SA is evident. 


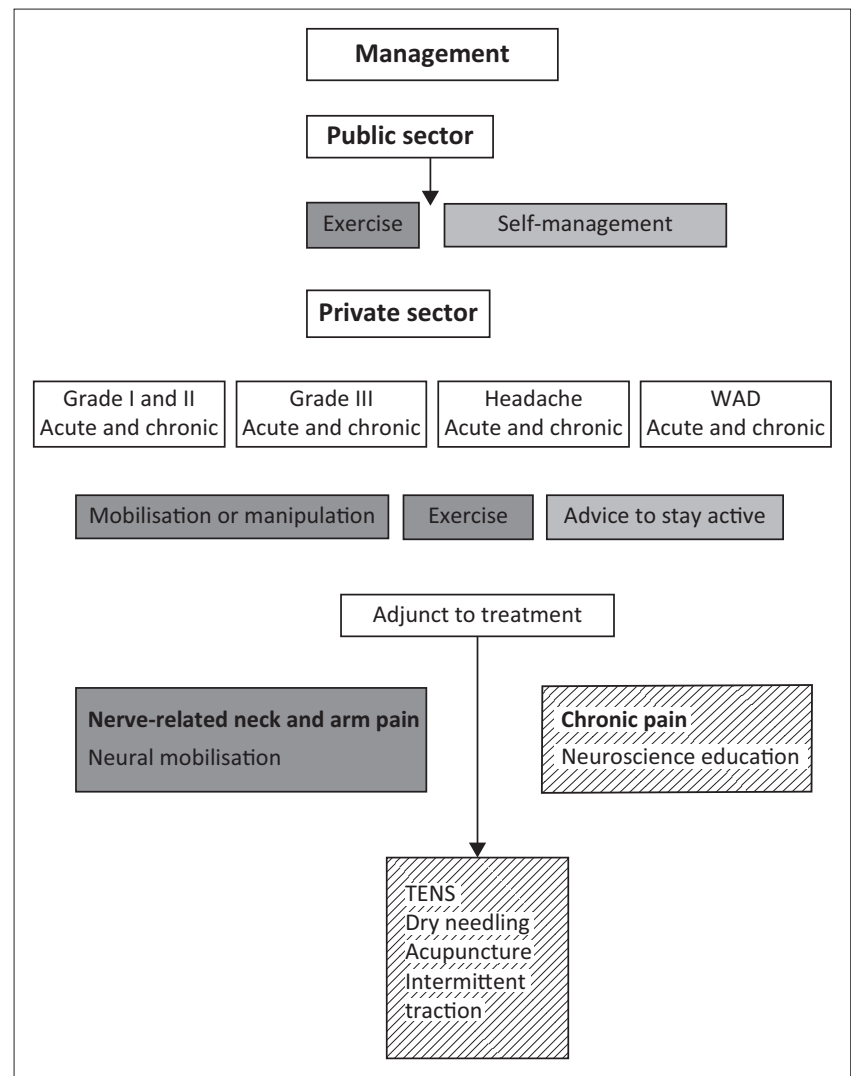

Note: Systematic reviews, dark gray; randomised controlled trials, line strip; expert opinion, light gray.

TENS, transcutaneous electrical nerve stimulation; WAD, whiplash-associated disorders. FIGURE 3: Management of neck pain.

In summary:

- Neck pain is common and can be debilitating.

- Symptoms tend to improve over the first 6-8 weeks after which the symptoms will remain the same.

- The prognosis for full recovery at 1-year follow-up is poor.

- A comprehensive assessment and the use of outcome measures to monitor change over time are important.

- Strengthening exercise of the neck and scapula-thoracic area is of benefit to most types of neck pain.

- Mobilisation or manipulation improves pain over the short, intermediate and long term.

- Other physical modalities such as dry needling, TENS, laser and intermittent traction may be used as adjuncts to treatment.

\section{Acknowledgements Competing interests}

The authors declare that they have no financial or personal relationships that may have inappropriately influenced them in writing this article.

\section{Authors' contributions}

C.A.B. was responsible for the concept and writing of the article. A.R. was responsible for the concept and critical review. B.O. was responsible for the concept and critical review.

\section{Ethical considerations}

This article followed all ethical standards for research without direct contact with human or animal subjects.

\section{Funding}

The authors declare that they have not received any financial support for the writing of the article.

\section{Data availability statement}

Data sharing is not applicable to this article as no new data were created or analysed in this study.

\section{Disclaimer}

The views expressed in the submitted article are the authors' own and not an official position of the institution or funder.

\section{References}

Audette, I., Dumas, J., Côté, J.N. \& De Serres, S.J., 2010, 'Validity and between-day reliability of the cervical range of motion (CROM) device', Journal of Orthopaedic \& Sports Physical Therapy 40(5), 318-323. https://doi.org/10.2519/jospt.2010.3180

Basson, A., Olivier, B., Ellis, R.F., Coppieters, M.W., Stewart, A. \& Mudzi, W., 2017a, 'The effectiveness of neural mobilization for neuromusculoskeletal conditions: A systematic review and meta-analysis', Journal of Orthopaedic \& Sports Physical Therapy 47(9), 593-615. https://doi.org/10.2519/jospt.2017.7117

Basson, C.A., Stewart, A. \& Mudzi, W., 2017b, 'The effect of neural mobilisation on cervico-brachial pain', PhD thesis, University of the Witwatersrand.

Bennett, M., 2001, 'The LANSS Pain Scale: The Leeds assessment of neuropathic symptoms and signs', Pain 92(1-2), 147-157. https://doi.org/10.1016/S03043959(00)00482-6

Bier, J.D., Scholten-Peeters, W.G.M., Staal, J.B., Pool, J., Van Tulder, M.W., Beekman, E. et al., 2018, 'Clinical practice guideline for physical therapy assessment and treatment in patients with nonspecific neck pain', Physical Therapy 98(3), 162-171. https://doi.org/10.1093/ptj/pzx118

Blanpied, P.R., Gross, A.R., Elliott, J.M., Devaney, L.L., Clewley, D., Walton, D.M. et al., 2017, 'Neck pain guidelines: Revision 2017', Journal of Orthopaedic \& Sports Physical Therapy 47(7), 511-512. https://doi.org/10.2519/jospt.2017.0507

Blyth, F., 2017, 'The global burden of neuropathic pain', Pain 159(3), 614-617. https://doi.org/10.1097/j.pain.0000000000001127

Bouhassira, D., Attal, N., Alchaar, H., Boureau, F., Brochet, B., Bruxelle, J. et al., 2005 'Comparison of pain syndromes associated with nervous or somatic lesions and development of a new neuropathic pain diagnostic questionnaire (DN4)', Pain 114(1-2), 29-36. https://doi.org/10.1016/j.pain.2004.12.010

Bradshaw, D., Groenewald, P., Laubscher, R., Nannan, N., Nojilana, B., Norman, R. et al., 2003, Initial burden of disease estimates for South Africa, 2000, 2003 edn., South Africa Medical Research Council, Cape Town.

Brink, Y., Crous, L.C., Louw, Q.A., Grimmer-Somers, K. \& Schreve, K., 2009, 'The association between postural alignment and psychosocial factors to uppe quadrant pain in high school students: A prospective study', Manual Therapy 14(6), 647-653. https://doi.org/10.1016/j.math.2009.02.005

Bussières, A.E., Stewart, G., Al-Zoubi, F., Decina, P., Descarreaux, M., Hayden, J. et al., 2016, 'The treatment of neck pain-associated disorders and whiplash-associated disorders: A clinical practice guideline', Journal of Manipulative and Physiological Therapeutics 39(8), 523-564.e27. https://doi.org/10.1016/j.jmpt.2016.08.007

Chetty, S., Baalbergen, E., Bhigjee, A.I., Kamerman, P., Ouma, J., Raath, R. et al. 2012 'Clinical practice guidelines for management of neuropathic pain: Expert panel recommendations for South Africa', South African Medical Journal 102(5), 312-325. https://doi.org/10.7196/SAMJ.5472

Childs, J.D., Cleland, J.A., Elliott, J.M., Teyhen, D.S., Wainner, R.S., Whitman, J.M et al 2008, 'Neck pain: Clinical practice guidelines linked to the international classification of functioning, disability, and health from the Orthopedic Section of the American Physical Therapy Association', Journal of Orthopaedic \& Sports Physical Therapy 38(9), A1-A34. https://doi.org/10.2519/jospt.2008.0303

Cohen, S.P. \& Hooten, W.M., 2017, 'Advances in the diagnosis and management of neck pain', BMJ 358. https://doi.org/10.1136/bmj.j3221

Coons, S.J., Rao, S., Keininger, D.L. \& Hays, R.D., 2000, 'A comparative review of generic quality-of-life instruments', Pharmacoeconomics 17(1), 13-35. https://doi.org/ 10.2165/00019053-200017010-00002

Cooper, M.A., Kluding, P.M. \& Wright, D.E., 2016, 'Emerging relationships between exercise, sensory nerves, and neuropathic pain', Frontiers in Neuroscience 10, 372 https://doi.org/10.3389/fnins.2016.00372

Daffner, S.D., Hilibrand, A.S., Hanscom, B.S., Brislin, B.T., Vacarro, A.R. \& Albert, T.J. 2003 , 'Impact of neck and arm pain on overall health status', Spine 28(17), 2030-2035. https://doi.org/10.1097/01.BRS.0000083325.27357.39 
Day, J.M., Willoughby, J., Pitts, D.G., Mccallum, M., Foister, R. \& Uhl, T.L., 2014, 'Outcomes following the conservative management of patients with non-radicular peripheral neuropathic pain', Journal of Hand Therapy 27(7), 192-199; quiz 200. https://doi.org/10.1016/j.jht.2014.02.003

De Pauw, R., Kregel, J., De Blaiser, C., Van Akeleyen, J., Logghe, T., Danneels, L. et al., 2015 , 'Identifying prognostic factors predicting outcome in patients with chronic neck pain after multimodal treatment: A retrospective study', Manual Therapy 20(4), 592-597. https://doi.org/10.1016/j.math.2015.02.001

Doth, A.H., Hansson, P.T., Jensen, M.P. \& Taylor, R.S., 2010, 'The burden of neuropathic pain: A systematic review and meta-analysis of health utilities', Pain 149(2), 338-344. https://doi.org/10.1016/j.pain.2010.02.034

Edwards, I., Jones, M., Carr, J., Braunack-Mayer, A. \& Jensen, G.M., 2004, 'Clinical reasoning strategies in physical therapy', Physical Therapy 84(4), 312-330.

Fillingim, R.B., Loeser, J.D., Baron, R. \& Edwards, R.R., 2016, 'Assessment of chronic pain: Domains, methods, and mechanisms', The Journal of Pain 17(suppl 9), T10-T20. https://doi.org/10.1016/j.jpain.2015.08.010

Fredin, K. \& Lorås, H., 2017, 'Manual therapy, exercise therapy or combined treatment in the management of adult neck pain: A systematic review and meta-analysis' Musculoskeletal Science and Practice 31, 62-71. https://doi.org/10.1016/j.msksp. 2017.07.005

Geere, J.-A., Bartram, J., Bates, L., Danquah, L., Evans, B., Fisher, M.B. et al., 2018 'Carrying water may be a major contributor to disability from musculoskeletal disorders in low income countries: A cross-sectional survey in South Africa, Ghana disorders in low income countries: A cross-sectional survey in South Africa, Ghana
and Vietnam', Journal of Global Health 8(1), 010406. https://doi.org/10.7189/ jogh.08.010406

Graham, N., Gross, A.R., Carlesso, L.C., Santaguida, P.L., Macdermid, J.C., Walton, D. et al., 2013, 'An ICON overview on physical modalities for neck pain and associated disorders', The Open Orthopaedics Journal 7(Suppl 4), 440-460. https://doi.org/ 10.2174/1874325001307010440

Grant, T., 2006, 'Problems of communicative competence in multi-cultural medical encounters in South African health services', Curationis 29(4), 54-60.

Grichnik, K.P. \& Ferrante, F.M., 1991, 'The difference between acute and chronic pain', Mount Sinai Journal of Medicine 58(3), 217-220.

Griffin, A., Leaver, A.M. \& Moloney, N., 2017, 'General exercise does not improve long-term pain and disability in individuals with whiplash-associated disorders: A systematic review', Journal of Orthopaedic \& Sports Physical Therapy 47(7), 1-29. https://doi.org/10.2519/jospt.2017.7081

Gross, A., Langevin, P., Burnie, S.J., Bedard-Brochu, M.-S., Empey, B., Dugas, E. et al., 2015, 'Manipulation and mobilisation for neck pain contrasted against an inactiv control or another active treatment', Cochrane Database of Systematic Reviews 9 CD004249. https://doi.org/10.1002/14651858.CD004249.pub4

Gross, A.R., Paquin, J.P., Dupont, G., Blanchette, S., Lalonde, P., Cristie, T. et al., 2016 'Exercises for mechanical neck disorders: A Cochrane review update', Manual Therapy 24, 25-45. https://doi.org/10.1016/j.math.2016.04.005

Guzman, J., Haldeman, S., Carroll, L.J., Carragee, E.J., Hurwitz, E.L., Peloso, P. et al., 2009 , 'Clinical practice implications of the bone and joint decade $2000-2010$ task force on neck pain and its associated disorders: From concepts and findings to
recommendations', Journal of Manipulative and Physiological Therapeutics 32(2) recommendations', Journal of Manipulative and Physiologica

Haanpää, M., Attal, N., Backonja, M., Baron, R., Bennett, M., Bouhassira, D. et al., 2011, 'NeuPSIG guidelines on neuropathic pain assessment', Pain 152(1), 14-27. https://doi.org/10.1016/j.pain.2010.07.031

Haldeman, S., Johnson, C.D., Chou, R., Nordin, M., Côté, P., Hurwitz, E.L. et al., 2018 'The global spine care initiative: Classification system for spine-related concerns', European Spine Journal 27(suppl 6), 889-900.

Hall, T.M., Robinson, K.W., Fujinawa, O., Akasaka, K. \& Pyne, E.A., 2008, 'Interteste reliability and diagnostic validity of the cervical flexion-rotation test', Journal of Manipulative and Physioogical Therapeutics 31(4), 293-300. https://doi.org/ Manipulative and Physioog

Hasumi, T. \& Jacobsen, K.H., 2014, 'Healthcare service problems reported in a national survey of South Africans', International Journal for Quality in Health Care 26(4), 482-489. https://doi.org/10.1093/intqhc/mzu056

Health Professions Council of South Africa, 2018, Registered persons with the council [Online], Pretoria, viewed 02 July 2018, from https://www.hpcsa.co.za/Publications/ Statistics

Hogg-Johnson, S., Van Der Velde, G., Carroll, L.J., Holm, L.W., Cassidy, J.D., Guzman, J. et al., 2008, 'The burden and determinants of neck pain in the general population: Results of the bone and joint decade 2000-2010 task force on neck pain and its associated disorders', Spine (Phila Pa 1976) 33(4S), S39-S51. https://doi.org/ 10.1097/BRS.0b013e31816454c8

Holdgate, A., Asha, S., Craig, J. \& Thompson, J., 2003, 'Comparison of a verbal numeric rating scale with the visual analogue scale for the measurement of acute pain Emergency Medicine (Fremantle) 15(5-6), 441-446. https://doi.org/10.1046/ j.1442-2026.2003.00499.x

Hoving, J.L., De Vet, H.C.W., Koes, B.W., Van Mameren, H., Deville, W.L.J.M., Van De Windt, D.A.W.M. et al., 2006, 'Manual therapy, physical therapy, or continued care by the general practitioner for patients with neck pain', Clinical Journal of Pain 22(4), 370-377. https://doi.org/10.1097/01.ajp.0000180185.79382.3f

Hoy, D., March, L., Woolf, A., Blyth, F., Brooks, P., Smith, E. et al., 2014, 'The global burden of neck pain: Estimates from the global burden of disease 2010 study', Annals of Rheumatic Diseases 73(7), 1309-1315. https://doi.org/10.1136/ annrheumdis-2013-204431

Huisman, P.A., Speksnijder, C.M. \& De Wijer, A., 2013, 'The effect of thoracic spine manipulation on pain and disability in patients with non-specific neck pain A systematic review', Disability and Rehabilitation 35(20), 1677-1685. https://doi. org/10.3109/09638288.2012.750689
Hurwitz, E.L., Randhawa, K., Yu, H., Côté, P. \& Haldeman, S., 2018, 'The global spine care initiative: A summary of the global burden of low back and neck pain studies', European Spine Journal 27(Suppl 6), 796-801. https://doi.org/10.1007/s00586017-5432-9

Hush, J.M., Lin, C.C., Michaleff, Z.A., Verhagen, A. \& Refshauge, K.M., 2011, 'Prognosis of acute idiopathic neck pain is poor: A systematic review and meta-analysis', Archives of Physical Medicine and Rehabilitation 92(5), 824-829. https://doi.org/ 10.1016/j.apmr.2010.12.025

Hutting, N., Kerry, R., Coppieters, M.W. \& Scholten-Peeters, G.G.M., 2018, 'Considerations to improve the safety of cervical spine manual therapy', Musculoskeletal Science and Practice 33, 41-45. https://doi.org/10.1016/j.msksp.2017.11.003

International Association for the Study of Pain, 2011, IASP Taxonomy [Online], IASP Press, Seattle, viewed 09 March 2014, from https://www.iasp-pain.org/ Education/Content.aspx?ItemNumber=1698\#Neuropathicpain.

Jakobsen, E.L.T., Biering, K., Kærgaard, A., Dalbøge, A. \& Andersen, J.H., 2018, 'Long term prognosis for neck-shoulder pain and disorders: A 14-year follow-up study', Occupational and Environmental Medicine 75(2), 90. https://doi.org/10.1136/ oemed-2017-104422

Karels, C.H., Bierma-Zeinstra, S.M., Burdorf, A., Verhagen, A.P., Nauta, A.P. \& Koes, B.W., 2007, 'Social and psychological factors influenced the course of arm, neck and shoulder complaints', Journal of Clinical Epidemiology 60(8), 839-848. https://doi.org/10.1016/j.jclinepi.2006.11.012

Kim, R., Wiest, C., Clark, K., Cook, C. \& Horn, M., 2018, 'Identifying risk factors for firstepisode neck pain: A systematic review', Musculoskeletal Science and Practice 33, 77-83. https://doi.org/10.1016/j.msksp.2017.11.007

Kroeling, P., Gross, A., Graham, N., Burnie, S.J., Szeto, G., Goldsmith, C.H. et al., 2013 , 'Electrotherapy for neck pain', Cochrane Database of Systematic Reviews [Online] 8, Art. CD004251. https://doi.org/10.1002/14651858.CD004251.pub5

Kuhn, J.E., 2016, 'Why measure outcomes?', Instructional Course Lectures 65, 583-586.

Landén Ludvigsson, M., Peterson, G. \& Peolsson, A., 2018, 'Neck-specific exercise may reduce radiating pain and signs of neurological deficits in chronic whiplash Analyses of a randomized clinical trial', Scientific Reports 8(1), 12409. https://doi. org/10.1038/s41598-018-30556-w

Lindgren, L., 2008, 'Preface: Neck pain and the decade of the bone and joint 2000-2010', Spine 33(4S), S1-S2. https://doi.org/10.1097/BRS.0b013e3181643f14

Louw, A., Diener, I., Butler, D.S. \& Puentedura, E.J., 2011, 'The effect of neuroscience education on pain, disability, anxiety, and stress in chronic musculoskeletal pain', Archives of Physical Medicine and Rehabilitation 92(12), 2041-2056. https://doi. org/10.1016/j.apmr.2011.07.198

Mafanya, C. \& Rhoda, A., 2011, 'Predictors of neck pain amongst South African youth', African Journal for Physical, Health Education, Recreation and Dance (suppl), 82-89. https://doi.org/10.4314/ajpherd.v17i3.68076

Malfliet, A., Kregel, J., Coppieters, I., Meeus, M., Roussel, N., Cagnie, B. et al., 2018 'Effect of pain neuroscience education combined with cognition-targeted motor control training on chronic spinal pain: A randomized clinical trial', JAMA Neurology 75(7), 808-817. https://doi.org/10.1001/jamaneurol.2018.0492

Mash, B., Fairall, L., Adejayan, O., Ikpefan, O., Kumari, J., Mathee, S. et al., 2012, 'A morbidity survey of South African primary care', PLoS One 7(3), e32358. https:// doi.org/10.1371/journal.pone.0032358

Mejuto-Vázquez, M.J., Salom-Moreno, J., Ortega-Santiago, R., Truyols-Domínguez, S. \& Fernandez-De-Las-Peñas, C., 2014, 'Short-term changes in neck pain, widespread pressure pain sensitivity, and cervical range of motion after the application of trigger point dry needling in patients with acute mechanical neck pain: A randomized clinical trial', Journal of Orthopaedic \& Sports Physical Therapy 44(4), 252-260. https://doi.org/10.2519/jospt.2014.5108

Merskey, H. \& Bogduk, N., 2011, 'Part III: Pain terms, a current list with definitions and notes on usage', 1994 edn., IASP Press, Seattle.

Miller, J., Gross, A., D’Sylva, J., Burnie, S.J., Goldsmith, C.H., Graham, N. et al., 2010 'Manual therapy and exercise for neck pain: A systematic review', Manual Therapy 15(4), 334-354. https://doi.org/10.1016/j.math.2010.02.007

Miller, R.P., Kori, S.H. \& Todd, D.D., 1991, 'The Tampa scale: A measure of kinesiophobia', The Clinical Journal of Pain 7(1), 51. https://doi.org/10.1097/00002508-199103000 00053

Moloney, N., Hall, T. \& Doody, C., 2015, 'Divergent sensory phenotypes in nonspecific arm pain: Comparisons with cervical radiculopathy', Archives of Physical Medicin and Rehabilitation 96(2), 269-275. https://doi.org/10.1016/j.apmr.2014.09.015

National Department of Health, 2015, Framework and strategy for disability and rehabilitation services in South Africa 2015 - 2020, Department of Health, Pretoria.

National Department of Health, 2016, National Health Insurance [Online], viewed 27 March 2019, from, https://www.health.gov.za/index.php/nhi.

Phillips, B., Ball, C., Sackett, D., Badenoch, D., Straus, S., Haynes, B. et al., 2009, Oxford centre for evidence-based medicine - Levels of evidence, 1998 edn., Centre of Evidence Based Medicine, Oxford.

Pool, J.J.M., Ostelo, R.W.J.G., Knol, D., Bouter, L.M. \& De Vet, H.C.W., 2010, 'Are psychological factors prognostic indicators of outcome in patients with sub-acute neck pain?', Manual Therapy 15(1), 111-116. https://doi.org/10.1016/j.math 2009.08.001

Racicki, S., Gerwin, S., Diclaudio, S., Reinmann, S. \& Donaldson, M., 2013, 'Conservative physical therapy management for the treatment of cervicogenic headache: A systematic review', The Journal of Manual \& Manipulative Therapy 21(2), 113-124. https://doi.org/10.1179/2042618612Y.0000000025

Ranchod, S., Adams, C., Burger, R., Carvounes, A., Dreyer, K., Smith, A. et al., 2017, South Africa's hospital sector: Old divisions and new developments, in A. Padarath \& P. Barron (eds.), South African health review 2017, pp. 101-110, Health Systems Trust, Durban. 
Rasmussen, H., Kent, P., Kjaer, P. \& Kongsted, A., 2015, 'In a secondary care setting, differences between neck pain subgroups classified using the Quebec task force classification system were typically small: A longitudinal study', BMC Musculoskeletal classification system were typically small: A longitudinal study', BMCM
Disorders 16(1), 150. https://doi.org/10.1186/s12891-015-0609-z

Rasmussen-Barr, E., Grooten, W.J.A., Hallqvist, J., Holm, L.W. \& Skillgate, E., 2014, 'Are job strain and sleep disturbances prognostic factors for neck/shoulder/arm pain? A cohort study of a general population of working age in Sweden', BMJ Open 4(7) A cohort study of a general population of working age in Swed
e005103. https://doi.org/10.1136/bmjopen-2014-005103

Rice, A., Smith, B. \& Blyth, F., 2016, 'Pain and the global burden of disease', Pain 157(4), 791-796. https://doi.org/10.1097/j.pain.0000000000000454

Rubinstein, S.M., Pool, J.J., Van Tulder, M.W., Riphagen, II \& De Vet, H.C., 2007 'A systematic review of the diagnostic accuracy of provocative tests of the neck for diagnosing cervical radiculopathy', European Spine Journal 16(3), 307-319. https://doi.org/10.1007/s00586-006-0225-6

Rubio-Ochoa, J., Benítez-Martínez, J., Lluch, E., Santacruz-Zaragozá, S., GómezContreras, P. \& Cook, C.E., 2016, 'Physical examination tests for screening and diagnosis of cervicogenic headache: A systematic review', Manual Therapy 21 35-40. https://doi.org/10.1016/j.math.2015.09.008

Rushton, A., Rivett, D., Carlesso, L., Flynn, T., Hing, W. \& Kerry, R., 2014, 'International framework for examination of the cervical region for potential of cervical arterial dysfunction prior to orthopaedic manual therapy intervention', Manual Therapy 19(3), 222-228. https://doi.org/10.1016/j.math.2013.11.005

Sackett, D.L., Rosenberg, W.M.C., Gray, J.A.M., Haynes, R.B. \& Richardson, W.S., 1996 'Evidence based medicine: What it is and what it isn't', British Medical Journal 312(7023), 71-72. https://doi.org/10.1136/bmj.312.7023.71

Salt, E., Wright, C., Kelly, S. \& Dean, A., 2011, 'A systematic literature review on the effectiveness of non-invasive therapy for cervicobrachial pain', Manual Therapy 16(1), 53-65. https://doi.org/10.1016/j.math.2010.09.005

Sleijser-Koehorst, M.L.S., Coppieters, M.W., Heymans, M.W., Rooker, S., Verhagen, A.P. \& Scholten-Peeters, G.G.M., 2018, 'Clinical course and prognostic models for the conservative management of cervical radiculopathy: A prospective cohort study',
European Spine Journal, 27(11), 2710-2719. https://doi.org/10.1007/s00586European Spin

Smart, K.M., Blake, C., Staines, A. \& Doody, C., 2012, 'Self-reported pain severity, quality of life, disability, anxiety and depression in patients classified with "nociceptive", "peripheral neuropathic" and "central sensitisation" pain. The "nociceptive", "peripheral neuropathic" and "central sensitisation" pain. The Manual Therapy 17(2), 119-125. https://doi.org/10.1016/j.math.2011.10.002

Smith, B.H., Torrance, N., Bennett, M.I. \& Lee, A.J., 2007, 'Health and quality of life associated with chronic pain of predominantly neuropathic origin in the community', Clinical Journal of Pain 23(2), 143-149. https://doi.org/10.1097/01. ajp.0000210956.31997.89

Smith, L., Louw, Q., Crous, L. \& Grimmer-Somers, K., 2009, 'Prevalence of neck pain and headaches: Impact of computer use and other associative factors', Cephalalgia 29(2), 250-257. https://doi.org/10.1111/j.1468-2982.2008.01714.x

Snodgrass, S.J., Cleland, J.A., Haskins, R. \& Rivett, D.A., 2014, 'The clinical utility of cervical range of motion in diagnosis, prognosis and evaluating the effects of manipulation: A systematic review', Physiotherapy 100(4), 290-304. https://doi. org/10.1016/j.physio.2014.04.007

Sterling, M. \& Pedler, A., 2009, 'A neuropathic pain component is common in acute whiplash and associated with a more complex clinical presentation', Manual Therapy 14(2), 173-179. https://doi.org/10.1016/j.math.2008.01.009

Sullivan, M.J.L., Bishop, S.R. \& Pivik, J., 1995, 'The pain catastrophizing scale: Development and validation', Psychological Assessment 7(4), 524-532. https:// doi.org/10.1037/1040-3590.7.4.524

Tampin, B., Slater, H. \& Briffa, N., 2013, 'Neuropathic pain components are common in patients with painful cervical radiculopathy, but not in patients with nonspecific neck-arm pain', Clinical Journal of Pain 29(10), 846-856. https://doi.org/10.1097/ AJP.0b013e318278d434

Teasell, R.W., Mcclure, J., Walton, D., Pretty, J., Salter, K., Meyer, M. et al., 2010a 'A research synthesis of therapeutic interventions for whiplash-associated 'A research synthesis of therapeutic interventions for whiplash-associated
disorder (WAD): Part 3 - Interventions for subacute WAD', Pain Research \& disorder (WAD): Part 3 - Interventions for subacute WAD', Pain Resea
Management: The Journal of the Canadian Pain Society 15(5), 305-312.

Teasell, R.W., Mcclure, J., Walton, D., Pretty, J., Salter, K., Meyer, M. et al., 2010b, 'A research synthesis of therapeutic interventions for whiplash-associated disorder: 'Art 1 - Overview and summary', Pain Research \& Management: The Journal of the Part 1 - Overview and summary', Pain Research \& Management: The Journal of
Canadian Pain Society 15(5), 287-294. https://doi.org/10.1155/2010/108685

Teasell, R.W., Mcclure, J., Walton, D., Pretty, J., Salter, K., Meyer, M. et al., 2010c, 'A research synthesis of therapeutic interventions for whiplash-associated disorders (WAD): Part 2 interventions for acute WAD, Pain Research \& Management: The Journal of the Canadian Pain Society 15(5), 295-304. https://
doi.org/10.1155/2010/106593
Thompson, D.P., Urmston, M., Oldham, J.A. \& Woby, S.R., 2010, 'The association between cognitive factors, pain and disability in patients with idiopathic chronic neck pain', Disability \& Rehabilitation 32(21), 1758-1767. https://doi.org/ chronic neck pain', Disability \&
$10.3109 / 09638281003734342$

Thoomes, E.J., Scholten-Peeters, W., Koes, B., Falla, D. \& Verhagen, A.P., 2013, 'The effectiveness of conservative treatment for patients with cervical radiculopathy. A systematic review', Clinical Journal of Pain 29(12), 1073-1086. https://doi.org/10.1097/AJP.0b013e31828441fb

Turk, D.C., Fillingim, R.B., Ohrbach, R. \& Patel, K.V., 2016, 'Assessment of psychosocia and functional impact of chronic pain', Journal of Pain 17(9 suppl), T21-T49. https://doi.org/10.1016/j.jpain.2016.02.006

Van Hulst, R., Van Oostrom, S.H., Ostelo, R.W.J.G., Verschuren, W.M.M. \& Picavet, H.S., 2016, 'Long-term patterns of chronic complaints of the arms, neck and shoulders and their determinants - the doetinchem cohort study', Pain 157(5), 1114-1121. https://doi.org/10.1097/j.pain.0000000000000488

Van Trijffel, E., Anderegg, Q., Bossuyt, P.M. \& Lucas, C., 2005, 'Inter-examiner reliability of passive assessment of intervertebral motion in the cervical and lumbar spine: A systematic review', Manual Therapy 10(4), 256-269. https://doi.org/10.1016/j. math.2005.04.008

Vasseljen, O., Woodhouse, A., Bjørngaard, J.H. \& Leivseth, L., 2013, 'Natural course of acute neck and low back pain in the general population: The HUNT study', Pain 154(8), 1237-1244. https://doi.org/10.1016/j.pain.2013.03.032

Vos, T., Allen, C., Arora, M., Barber, R.M., Bhutta, Z.A., Brown, A. et al., 2016, 'Global, regional and national incidence, prevalence and years lived with disability for 310 diseases and injuries, 1990-2015: A systematic analysis for the global burden of disease study 2015', The Lancet 388(10053), 1545-1602. https://doi.org/10.1016/ disease study 2015, The

Vos, T., Flaxman, A.D., Naghavi, M., Lozano, R., Michaud, C., Ezzati, M. et al., 2012, 'Years lived with disability (YLDs) for 1160 sequelae of 289 diseases and injuries 1990-2010: A systematic analysis for the global burden of disease study 2010', 1990-2010: A systematic analysis for the global burden of disease study 2010', The Lancet
$61729-2$

Waddell, G., Newton, M. Henderson, I., Somerville, D. \& Main, C.J., 1993 'A fearavoidance beliefs questionnaire (FABO) and the role of fear-avoidance beliefs in chronic low back pain and disability', Pain 52(2), 157-168. https://doi.org/ 10.1016/0304-3959(93)90127-B

Wainner, R.S., Fritz, J.M., Irrgang, J.J., Boninger, M.L., Delitto, A. \& Allison, S., 2003 'Reliability and diagnostic accuracy of the clinical examination and patient selfreport measures for cervical radiculopathy', Spine 28(1), 52-62. https://doi. org/10.1097/00007632-200301010-00014

Walton, D.M., Carroll, L.J., Kasch, H., Sterling, M., Verhagen, A.P., Macdermid, J.C. et al., 2013, 'An overview of systematic reviews on prognostic factors in neck pain: Results from the international collaboration on neck pain (ICON) project', The Open Orthopaedics Journal 7(Suppl 4), 494-505. https://doi.org/10.2174/ The Open Orthopaedics
1874325001307010494

Walton, D.M., Eilon-Avigdor, Y, Wonderham, M. \& Wilk, P., 2014a, 'Exploring the clinical course of neck pain in physical therapy: A longitudinal study', Archives of Physical Medicine and Rehabilitation 95(2), 303-308. https://doi.org/10.1016/j. apmr.2013.09.004

Walton, D.M., Levesque, L, Payne, M. \& Schick, J, 2014b 'Clinical pressure pain threshold testing in neck pain: Comparing protocols, responsiveness and association with psychological variables', Physical Therapy 94(6), 827-837. association with psychological variab
https://doi.org/10.2522/ptj.20130369

Wirth, B. Humphreys, B.K. \& Peterson, C. 2016, 'Importance of psychological factors for the recovery from a first episode of acute non-specific neck pain: A longitudinal observational study', Chiropractic \& Manual Therapies 24, 1-10. https://doi. observational study', Chiropractic
org/10.1186/s12998-016-0090-2

World Health Organization, 2010, South Africa factsheets of health statistics, viewed n.d., from https://www.aho.afro.who.int/profiles information/images/c/c7/South Africa-Statistical_Factsheet.pdf?ua=1.

Yang, H., Hitchcock, E., Haldeman, S., Swanson, N., Lu, M.-L., Choi, B. et al. 2016 'Workplace psychosocial and organizational factors for neck pain in workers in the United States', American Journal of Industrial Medicine 59(7), 549-560. https:// doi.org/10.1002/ajim.22602

Zito, G., Jull, G. \& Story, I., 2006, 'Clinical tests of musculoskeletal dysfunction in the diagnosis of cervicogenic headache', Manual Therapy 11(2), 118-129. https://doi. diagnosis of cervicogenic headache',
org/10.1016/j.math.2005.04.007

Zungu, L.I. \& Ndaba, E.F., 2009, 'Self-reported musculoskeletal disorders among office workers in a private hospital in South Africa: Prevalence and relationship to physical demands of the work', Occupational Health Southern Africa (September/ October), 25-30. 